\title{
MÁS ALLÁ DE LA VASIJA: LA CERÁMICA DE BERNARDO HOGAN A TRAVÉS DE SUS EXPOSICIONES (1984-2005)
}

\author{
BEYOND THE VESSEL: BERNARDO HOGAN'S \\ CERAMICS THROUGH HIS \\ EXHIBITIONS (1984-2005)
}

\author{
DANiEl Expósito SÁNChez \\ Universidad de Puerto Rico. Puerto Rico \\ daniel.exposito@upr.edu
}

\begin{abstract}
El presente artículo plantea un breve recorrido por la trayectoria del ceramista argentino Bernardo Hogan a través de sus exposiciones individuales celebradas entre 1984 y 2005. En ellas el artista, radicado en Puerto Rico desde 1968, desarrolló una producción basada principalmente en la vasija, a partir de la cual efectuaría múltiples variaciones sin perder nunca la esencia clásica de este singular recipiente.

Palabras clave: Bernardo Hogan, Cerámica, Vasija, Torno, Puerto Rico.
\end{abstract}

This article presents a brief journey across the career of the Argentine potter Bernardo Hogan through his solo exhibitions held between 1984 and 2005. The artist, who lives in Puerto Rico since 1968 , developed a production based mainly on the vessel. This unique form had multiple changes without losing its classic essence.

Keywords: Bernardo Hogan, Ceramic, Vessel, Potter's Wheel, Puerto Rico.

Puede decirse que la inmersión de Bernardo Hogan en el universo de la cerámica estuvo marcada por la casualidad. Su formación nada tuvo que ver con el arte, y su familia, dedicada a la ganadería, no influyó lo más mínimo en este aspecto. Tampoco su trabajo primitivo tuvo vinculación alguna con la plástica. Sería, ciertamente, su encuentro con Susana Espinosa y su posterior matrimonio los que asentarían las bases para su intensa dedicación al barro, la cual hoy, pese a sus 94 años, continúa ejerciendo en su taller sanjuanero de Miramar. A lo largo de poco más de cuatro décadas fue erigiendo un lenguaje propio, caracterizado por una excepcional predilección por la vasija y sus numerosas variantes, 
al que agregaría una reconocida pasión por la química y, por tanto, al mundo de los engobes y los esmaltes. Pero esta labor no se centró exclusivamente en la formulación de colores propios sino que, además, se concentraría en su faceta como docente, primero en la Liga de Estudiantes de Arte de San Juan para, más tarde, volcarse por completo en las aulas de Casa Candina ${ }^{1}$. Esas ocupaciones, sin embargo, no impidieron el desarrollo de un corpus artístico de gran solidez, expuesto en instituciones museísticas de países como Italia, Croacia, Francia, Venezuela, Estados Unidos, y que, como señaló Jaime Suárez, cautivaba “con su sencillez y elegancia"2.

Hogan nació en Arrecifes, al norte de la provincia de Buenos Aires, en 1921. Apenas tenemos noticias acerca de esta etapa inicial de su vida; sí sabemos, en cambio, que cursó estudios de meteorología gracias a la empresa de aerolíneas en la que trabajaba, ocupando posteriormente la gerencia de su sede en Trini$\mathrm{dad}^{3}$. La estancia en esta Antilla Menor supondría un giro radical en su existencia: allí conocería a Espinosa, quien hacía una escala a su vuelta de un viaje a Nueva York, y contraería nupcias con ella en 1962. La pareja permanecería en la república caribeña hasta que Bernardo decidió abandonar su puesto y, aconsejado por un colega residente en Cuba, marcharía a la isla vecina de Puerto Rico. Junto a éste montaría un negocio de producción de medallas con pocas aspiraciones, ya que pronto tuvieron que cerrar debido a la inatención y una evidente falta de iniciativa empresarial ${ }^{4}$. Durante ese tiempo Hogan comenzó a leer libros sobre cerámica, interesándose sobre todo por la naturaleza de los materiales, o sea, sus compuestos y preparación.

Coincidió este momento con el arranque de las primeras incursiones artísticas de Espinosa en San Juan, cuyo proceso creativo era seguido muy de cerca por su marido. La inquietud de Hogan por aquel medio abarcaba una observación concienzuda de cada uno de los pasos dados por su compañera, fueran o no acertados, lo que le llevaba a la preocupación de saber cuáles habían sido las claves para alcanzar ese fin determinado. "Bernardo comenzó a interesarse incluso en mis fracasos”, afirmaría Susana, "y me preguntaba qué había hecho mal, porqué tal

${ }^{1}$ Una visión sintética acerca de los orígenes de esta corporación sin fines de lucro con sede en una casona de Condado (San Juan) puede hallarse en EXPÓSITO SÁNCHEZ, Daniel: “'Navegando el laberinto': Ocho relatos para conocer la obra de Jaime Suárez”, en Jaime Suárez: El laberinto de la creación. Gurabo, P.R., 2015, p. 11.

2 SUÁREZ, Jaime: "Bernardo Hogan: Vasijas vasijas...", en Vasijas vasijas.... San Juan, P.R., 1984, s.f.

3 CANELLA, Sara: "La cerámica como punto de partida y de regreso", El Nuevo Día, 25 de septiembre de 1988, p. 71.

${ }^{4} \mathrm{El}$ dato fue aportado por el matrimonio argentino durante una entrevista que llevé a cabo en su domicilio de Miramar (San Juan) el 23 de marzo de 2014. 
pieza se me había roto" ". Esa búsqueda fue compensándose mediante la adquisición de una vasta bibliografía relativa a lo que denominó "la materia prima", el fundamento a partir del cual iría construyendo un ingente conocimiento autodidacta. A esa lectura, también, sumaría las clases de torno recibidas de mano de Frank DiGangi ${ }^{6}$, director de Isla del Sol, una de las fábricas de cerámica que, aún en los setenta, continuaba sus operaciones comerciales en el país como antes lo habían hecho Puerto Rican Pottery y Caribe China.

Las verdaderas aportaciones de Hogan a los murales comisionados por el Caribe Hilton a Espinosa ${ }^{7}$ no debieron ser, desde luego, especialmente relevantes. No hay duda de su participación en los mismos, al menos en el diseño de los medallones y en su instalación. Pero La Tierra y El Mar, las piezas de mayores dimensiones, aparecen firmados sólo por Espinosa y los esmaltes empleados en ambos trabajos eran comerciales, al contrario de lo que ocurriría en obras ulteriores. Por ello esta etapa, más bien, debió constituir lo que podríamos denominar el periodo de formación de nuestro incipiente artista: la teoría aprendida en los libros se veía complementada con el quehacer diario de su esposa que, de manera paulatina, se adentraba en los circuitos de la cerámica insular. La labor de ésta como jurado en los certámenes de la Asociación de Cerámica Artística y, principalmente, su adhesión al colectivo de la Galería Manos debió tener valiosas repercusiones para Hogan. Es lógico pensar en su asistencia a la conferencia dictada por Daniel Rhodes acerca de la preparación de los barros ${ }^{8}$, en este emblemático espacio del Centro de Convenciones, además de su fiel presencia en las constantes exposiciones celebradas en él. Estas y otras actividades, pues, ejercerían una influencia notable tanto en su concepción del medio como en el desafío que suponía enfrentarse a las formas en el torno, resueltas, al fin y al cabo, a través de una tenaz experimentación.

Se ha apuntado que en 1978 Hogan empezó a producir sus primeras obras, consistentes en "vasijas esmaltadas de gran sencillez y calidad". En efecto, no es extraño que se decidiera a aplicar ese saber acumulado mediante una serie de piezas tridimensionales, más teniendo presente que a esas alturas del decenio el

5 CANELLA, Sara: "La cerámica como punto de partida...", op. cit., p. 71.

${ }^{6}$ Véase la nota 4.

7 Dichas obras fueron encargadas a través del diseñador de interiores neoyorquino Bill Boydston. Para una breve descripción de ellas véase BENÍTEZ, Marimar: "Forma, color y espacio en los murales de Susana Espinosa”, en Susana Espinosa: Cerámicas. San Juan, P.R., 1981, pp. 11-12. Igualmente, EXPÓSITO SÁNCHEZ, Daniel: “Cerámica imaginada: Un itinerario por los murales de Susana Espinosa" (en prensa).

${ }^{8}$ AJS (Archivo Jaime Suárez), Rhodes y Manos en el Centro, recorte de prensa sin fechar, s.f.

9 AMHAA (Archivo Museo de Historia, Antropología y Arte, Universidad de Puerto Rico, Recinto de Río Piedras), Bernardo Hogan, hoja mecanografiada, s.f. 
taller del matrimonio argentino funcionaba a pleno rendimiento. Contaban con la asistencia de Isabel Rivera, antigua colaboradora de Espinosa en la citada factoría de Hal Lasky, para la elaboración de los conjuntos de gran formato, por lo que cada miembro del equipo cumplía un papel muy específico: mientras Rivera manejaba las piezas de molde, la dedicación de Espinosa se centraba en los platos, esculturas, y diseños dirigidos a una venta más comercial, a los que se añadían, obviamente, la realización de murales. Éstos, según Hogan, requerían de una atención mayor al resto: "Cuando Susana diseña un trabajo a comisión son largas las horas que empleamos en discutirlo. Estos son trabajos cuyo planeamiento es de suma importancia, pues deberán ser instalados en áreas específicas". Y, dentro de esa excepcionalidad, él jugaba un rol imprescindible dentro de lo que denominaba "mi mundo", es decir, "el de la preparación del barro, de formulación de engobes y esmaltes" 10 . De esos temas hablaría en un taller impartido en la mencionada Liga a finales de marzo de 1980. El programa ofrecería un total de cuatro conferencias con un denso ingrediente práctico, abarcando desde los pasos iniciales para ejecutar distintas variedades del material hasta el examen de las obras cocidas en el horno ${ }^{11}$.

Pero el acontecimiento que dio a conocer el nombre de Bernardo Hogan en el ambiente artístico puertorriqueño fue el premio ganado en el célebre Concorso Internazionale della Ceramica d'Arte de Faenza en 1982. No se trataba, empero, del primer ceramista en obtener este prestigioso galardón: en 1979 Ana Delia Rivera había estrenado la victoria boricua en la ciudad italiana, siendo seguida por Espinosa y Jaime Suárez en las ediciones consecutivas de 1980-1981². El de Hogan consistió, concretamente, en la medalla de oro concedida por la Confederazione Libere Associazioni Artigiane Italiane di Milano, y el laudo del jurado resaltaría, entre otras virtudes, la "expresión, inventiva, exploración en el uso de los materiales, calidad de los esmaltes, oficio y relación con las tendencias internacionales en el uso del barro"'13. Cinco fueron las piezas presentadas al certamen: tres vasijas y dos cuencos, herederos todos de un patrón similar fundamentado en la

${ }^{10}$ Ambas declaraciones han sido tomadas de HOGAN, Bernardo: "El taller de cerámica”, en Susana Espinosa..., op. cit., p. 18.

${ }^{11}$ Éste fue, ciertamente, uno de los factores que propició la creación de Casa Candina, fundada en agosto de ese año. Véase EXPÓSITO SÁNCHEZ, Daniel: "Navegando el laberinto...”, op. cit., p. 11. Aparte, “Taller de Cerámica En Liga Arte SJ”, El Mundo, 20 de marzo de 1980, p. 10-B; "Taller de cerámica en la Liga de Estudiantes", El Nuevo Día, 19 de marzo de 1980 , p. 60.

${ }^{12}$ LANDRÓN, Iris M.: "Ana Delia, medalla de oro para Puerto Rico", El Nuevo Día, 25 de septiembre de 1979, p. 24. Para el premio de Suárez, véase EXPÓSITO SÁNCHEZ, Daniel: "Navegando el laberinto...", op. cit., pp. 11-12. El de Espinosa fue reseñado en BOTHWELL DEL TORO, Frances M.: "Susana Espinosa”, Plástica, diciembre 1980, pp. 9-10.

13 BENÍTEZ, Marimar: "El premio de Hogan", El Nuevo Día, 9 de agosto de 1982, p. 38 . 
aparente sencillez de sus formas. En las primeras apostó por construcciones globulares y cilíndricas realizadas en el torno, con una boca estrecha, destacando en ellas unos blancos resplandecientes salpicados no sólo de lívidas manchas de color, sino de líneas centrales que delimitaban su superficie. Las segundas, por su lado, contrastaban con las anteriores tanto por la generosa amplitud de su zona superior como por la armonía del recipiente y la estrecha base que le servía de apoyo. Y, en ambos casos, se hacía patente un dominio de la técnica que iba más allá de la simple reproducción de referencias visuales.

Esa seguridad ante el proceso creativo debió conducirle a la organización de su primera exposición individual en diciembre de 1984, titulada Vasijas vasijas... y celebrada en Casa Candina. Apenas se conservan imágenes de esta muestra iniciática, pero son reveladoras las palabras con las que Suárez empezó el breve texto que acompaña al catálogo: "Las vasijas de Bernardo Hogan trascienden su funcionalidad sin negarla" ${ }^{14}$. No debe olvidarse que el supuesto uso de las obras efectuadas en cerámica había sido uno de los debates más encendidos de la plástica insular desde comienzos de los setenta, y esa cualidad "innata" justificaba, a ojos de muchos escultores, su carácter de arte "menor". Aunque los miembros de Estudio Caparra y de Galería Manos consiguieron demostrar justamente lo contrario, todavía en los años ochenta esa polémica pervivía en el alma de algunos de esos detractores ${ }^{15}$. De cualquier manera las de Hogan eran piezas que, por su mera condición de recipientes, podían ser tomadas a simple vista como objetos utilitarios, pero Suárez nuevamente matizaba este y otros aspectos singulares: "No responden a una necesidad de crear vasijas; responden a un impulso estético que lo lleva a investigar formas cerámicas en el torno alfarero"16. Ese aprendizaje "artesanal" que conllevaba la conocida máquina giratoria, en buena medida, motivaría en el artista una suerte de subordinación a su empleo más tradicional, asentado en la construcción de obras desde el interior hacia el exterior de sus formas.

Candina fue, asimismo, la receptora de su segunda exhibición, Forma, textura y color, inaugurada el 20 de abril de 1990. Tres conceptos éstos que desarrolló paulatinamente durante la segunda mitad del decenio anterior, en el cual su actividad había sido constante: participó en Faenza en 1984 y 1985, a lo que agregó un periplo por otras ciudades europeas, Vallauris y Zagreb, sedes de la Biennale Internationale de Céramique d'Art y de la World Triennial Exhibition of Small Ceramics, respectivamente; sus obras se expusieron en las múltiples colectivas de ceramistas montadas en el Instituto de Cultura, el Recinto de Río Piedras de la Universidad de Puerto Rico, el Museo de Arte de Ponce, y otras instituciones culturales de la isla, además de en colectivas como Art Under the Sun, en Nueva

${ }^{14}$ SUÁREZ, Jaime: “Bernardo Hogan...”, op. cit., s.f.

15 Al respecto, es de obligada consulta BENÍTEZ, Marimar: "Pablo Rubio: sobre el barro, la cerámica y la escultura", El Reportero, 10 de septiembre de 1983, pp. 8-9.

${ }^{16}$ SUÁREZ, Jaime. "Bernardo Hogan...", op. cit., s.f. 
York, o La cerámica de Puerto Rico, en Caracas ${ }^{17}$; y la sobresaliente producción de murales llevada a cabo en colaboración con Espinosa debió copar, junto a la elaboración de platos más comerciales, gran parte de su tiempo. Tampoco hay que olvidar su faceta como profesor en las clases ofertadas en la casona de Condado: a su cargo quedarían, como era de esperar, las relativas al manejo del torno y la formulación de esmaltes.

La flamante muestra tomó la propia naturaleza de la vasija como punto de partida. Afirmaba Hogan: "La vasija de cerámica me ha interesado como elemento universal que ha sido utilizado en todos los tiempos como objeto utilitario, ceremonial o decorativo. Me atrae la idea de la vasija como símbolo de tradición, forma que guarda y contiene". A lo que añadía: "El desarrollo de mis vasijas se fundamenta en el torneado y su relación con el círculo" 18 . Ambas sentencias reflejaban su preocupación por la pureza del diseño y su estructura, uniéndose una calculada previsión a la hora de elegir qué color destinaría a cada obra. El círculo, tal como apuntaba el artista, suponía el arranque del acto creativo, y el crecimiento de las paredes de barro mediante su giro en el torno se fundamentaba, en principio, sobre "formas simples, tradicionales y definidas". Una vez levantadas, éstas serían transformadas mediante la incorporación de elementos planos, evocativos, en ocasiones, de partes comunes a estos objetos como eran, por ejemplo, las asas, semejantes a orejetas; o a través de lo que Hogan denominó "brotes del interior" y que sugerían la representación de "nacimientos". Sea como fuere, y a pesar de su presunta similitud, cada pieza constituía una entidad en sí misma calificada como "una línea de pensamiento" ${ }^{19}$ : su autor las concebía como descripciones visuales de una memoria colectiva, enlazadas tanto al pasado como al momento presente, siendo él y sus contempladores los depositarios reales de esa cultura que las habían hecho persistir hasta la actualidad.

La recepción crítica de la exposición fue algo tibia, al contrario de lo que solía ser habitual en otras actividades de Candina. Se resaltaba la calidad técnica de Hogan ante el torno, pero, a la par, se reprobaba una falta de equilibrio entre los tres términos que daban nombre al evento. Frente a la destreza manifestada en la erección de las formas y el delicado tratamiento de sus caras, las tonalidades apagadas de las vasijas se consideraron fuera del contexto de un país tropical como Puerto Rico. El artífice, por otra parte, justificaba esa postura señalando que no deseaba "violar las superficies con tratamientos de mucho dramatismo y fuerza", aludiendo a que sus obras debían ser "sanas, fuertes, sin parecerlo, que no

${ }^{17}$ Estas sucintas referencias pueden completarse en la página que el artífice posee dentro del PROA (Programa de Asistencia al Artista), proyecto impulsado desde el Museo de Arte de Puerto Rico: mapr.org/en/museo/proa/artist/hogan-bernardo

${ }^{18}$ HOGAN, Bernardo: "Forma, textura y color", en Bernardo Hogan: Forma, textura y color. San Juan, P.R., 1990, s.f.

19 Ibídem. 
deslumbren", y evitando, así, "el uso de colores chillones". Este recato formal, según Hogan, no implicaba un obstáculo a la hora de apreciar sus cualidades estéticas, pues sus trabajos constituían un "interesante portador de pasiones". No pensó lo mismo el crítico Ernesto Ruiz de la Mata al preguntarse, no sin cierta ironía: “QQué pasiones serán estas? ¿Pasiones? ¿Cómo es posible tal afirmación cuando se manifiesta una actitud tan furibunda ante el color?". Ni tan siquiera el resto de miembros de Candina se librarían de tales ataques: sus conductas "más bien atemperantes" vendrían a ser portadoras de un futurible "mal gusto" que, manifestaba Ruiz de la Mata, "no responde a nuestro entorno"20.

Doce piezas más fueron instaladas en el Museo de Arte e Historia de San Juan, entre noviembre y diciembre de 1991. Si, hasta el momento, había predominado en sus vasijas un modo de visión panóptico, ahora la propuesta de Hogan dirigía la mirada del espectador hacia puntos muy concretos de las mismas. A tal efecto introdujo distintas planchas a lo largo de la superficie del cono, de manera que cada lado ofrecía un aspecto diferente uno del otro. Esas adherencias, igualmente, presentaban rasgos claramente geométricos que brindarían ciertos atisbos de profundidad gracias a la superposición de planos similares; una escasa distancia dejada entre ellos aumentaría su carácter volumétrico. De nuevo, textura y color cumplieron un objetivo más complementario que protagónico: blancos, negros, o verdes se alternarían con caras rugosas, de apariencia casi rocosa ${ }^{21}$, que subrayaban su naturaleza artística lejos de cualquier funcionalidad cotidiana.

Tanto éstas como otras vasijas se incorporaron a una antológica dedicada al artista en esa institución de la capital, titulada Bernardo Hogan. Cerámica: Obra en torno 1982-1995. La exposición había surgido por iniciativa de Elías López Sobá, director del Museo, quien invitó al ceramista a reunir un modesto número de obras, "quince o veinte", aunque, como apuntó el argentino, "la idea fue creciendo hasta convertirse en 71 obras, la mayor exposición de toda mi carrera"22. Diseño y montaje corrieron a cargo de Jorge Cancio, amigo del matrimonio y antiguo miembro de Manos, el cual seguiría una secuencia cronológica de la trayectoria del autor ${ }^{23}$. Casi en su totalidad, los préstamos se llevaron a cabo gracias a la generosidad de multitud de coleccionistas particulares, con la salvedad de algunas piezas fechadas a comienzos de los años ochenta que Hogan custodiaba en su

${ }^{20}$ Todas las citas han sido recogidas de RUIZ DE LA MATA, Ernesto: "Formas, textura y color de Bernardo Hogan", El Mundo, 6 de mayo de 1990, pp. 10-11.

${ }^{21}$ GARCÍA GUTIÉRREZ, Enrique: "Bernardo Hogan”, en Bernardo Hogan: Vasijas. San Juan, P.R., 1991, s.f.

22 ALEGRE BARRIOS, Mario: "Testimonio de una pasión inagotable", El Nuevo Día, 15 de agosto de 1995, p. 63.

${ }^{23}$ GARCÍA GUTIÉRREZ, Enrique: "BernardoHogan: Una lección magistral”, El Nuevo Día, 10 de septiembre de 1995, p. 13. 
domicilio, y otras pocas pertenecientes a entidades públicas y privadas ${ }^{24}$. Esa mirada retrospectiva le permitió recapitular acerca de los logros obtenidos durante tan breve lapso: el trabajo al lado de Espinosa desde finales de los sesenta, y su labor silenciosa, íntima, en el taller, se habían visto recompensados con un galardón de gran prestigio como el de Faenza; de ahí en adelante el reconocimiento de su producción en barro sería ascendente, siempre en consonancia con un lenguaje muy personal, en continua evolución, cuya vinculación al torno se destacaba por una fidelidad francamente encomiable. Señalaba el artista: "Ello no ha sido obstáculo para poder evolucionar dentro de este esquema y en obras de años recientes se puede percibir esta transformación, con formas que emanan y se desprenden del módulo central de la vasija"25.

Como mencionamos, esas variaciones ya se habían hecho evidentes en las obras expuestas a inicios de la década. Pero en esta ocasión no sólo haría recuento de sus hallazgos pasados sino que, junto a ello, aprovecharía la coyuntura para exhibir sus creaciones más recientes. Algunas, como Conos con base, mostraban dos de estas figuras con sus bocas completamente abiertas, insertas por su punta en el orificio central de una peana irregular. Se ha dicho al respecto que, desde ese apoyo, "la vasija es 'elevada' a un contexto puramente artístico", factor éste que acentuaría, en buena medida, el papel jugado por la pieza como objeto exclusivamente estético, "una metáfora de sí misma, exenta de cualquier otro argumento interpretativo" 26 . Otras, caso de Barrio Beatriz, hacían hincapié en cuestiones de mayor carga conceptual. Hogan situó aquí una vasija invertida acompañada de pedazos de barro sin procesar provenientes de esa barriada, localizada en el municipio de Cayey, esparcidos por el pedestal. A manera de un bodegón cerámico, esta pequeña instalación se planteaba como "un reconocimiento a los materiales y a los procedimientos del arte del alfarero"27. También, Vasija trasladada apostaría por superponer en ambas caras un fragmento de su corte longitudinal, mientras que Vasija con planos sumaba trozos puntiagudos en sus perfiles, semejantes a alas triangulares, lo que le otorgaba una perspectiva frontal eludiendo la multiplicidad de puntos de vista.

$\mathrm{Su}$ distanciamiento de las exigencias del torno se hizo más patente en sus dos siguientes exposiciones. La primera, El óvalo en la vasija, se inauguró en noviembre de 1998 en la Galería Botello, y constó de quince piezas que desafiaban la pureza de sus trabajos precedentes. Esta vez la construcción de tales obras no

${ }^{24}$ Todo ello, piezas y prestadores, aparece debidamente identificado en el catálogo de la muestra. Véase Bernardo Hogan. Cerámica: Obra en torno 1982-1995. San Juan, P.R., 1995, p. 6.

${ }^{25}$ ALEGRE BARRIOS, Mario: “Testimonio de una pasión...”, op. cit., p. 63.

${ }^{26}$ Las citas provienen de MIRANDA, José David: "Bernardo Hogan y la vasija como forma significativa”, en Bernardo Hogan. Cerámica..., op. cit, p. 11.

${ }^{27}$ GARCÍA GUTIÉRREZ, Enrique: "Bernardo Hogan: Una lección...”, op. cit., p. 15. 
se basaba estrictamente en el giro de la célebre máquina: tras generar en ella una forma cónica o cilíndrica, Hogan la dejaba secar con el objetivo de dividirla en dos mitades; efectuado este paso suprimía el fondo de esas partes, y a continuación las moldeaba y enlazaba en función del diseño buscado ${ }^{28}$. El proceso, de una aparente sencillez, otorgaba resultados diversos pero muy efectivos. Las dos paredes separadas eran unidas mediante una serie de delgados filamentos de barro que, simultáneamente, rehundían los espacios laterales obteniendo, de ese modo, la interrupción de su ritmo circular. Al diálogo establecido entre ambas fracciones se sumaba, asimismo, la incorporación de sus caras interiores, tratadas por el artífice como complemento o contraste de las exteriores a través de la aplicación de colores llamativos. Conseguidos éstos por una cocción a baja temperatura, la paleta consistiría en rojos, verdes, pardos y azules ${ }^{29}$ de fabricación propia, suministrados a lo largo de sus superficies de manera compacta. Aparte, en otras piezas limitó aquélla fragmentación colocando una fina cavidad que ayudaría a enfatizar la esbeltez de estas sutiles creaciones.

Más contundentes serían las obras expuestas en Sin Torno, cuya apertura tuvo lugar nuevamente en Botello, en febrero de 2001. Decía Hogan: "Trabajando el barro en el torno alfarero, las posibilidades son limitadas y claras las restricciones. Cada giro del torno es una fuerza dinámica, inmediata, que exige pensamiento y acción al mismo tiempo. Sin torno, el proceso de construcción se convierte en uno con más espacio para la concepción de la obra, ofreciendo tiempo para cambios imprevistos o planeados" 30 . Se refería, obviamente, al completo abandono de aquélla rueda a la hora de confeccionar tales propuestas, ya que su materialización partía del trabajo directo con la plancha. De ella surgiría una estructura casi plana, caracterizada por una suave curvatura en su centro y una boca notablemente estrecha, donde el color adquirió un mayor protagonismo: calificados como "pigmentación saturada" por García Gutiérrez ${ }^{31}$, la calidad de esos esmaltes, preparados personalmente por el artista, sobresaldría por la variedad de sus gradaciones cromáticas. Esto le permitió acentuar aún más las texturas, y la posibilidad de presentar sendos lados de la vasija como entidades independientes. Se trataba, pues, de un procedimiento más racional, meditativo en esencia, aunque no tan alejado como pudiera parecer de esos gestos provocados por la fuerza del torno.

Pese a tales indagaciones, el regreso a su antiguo instrumental se antojaba inevitable. Recent Works, su primera incursión en solitario en los Estados Unidos, puso a

${ }^{28}$ GARCÍA GUTIÉRREZ, Enrique: "El nuevo reto de Bernardo Hogan”, El Nuevo Día, 13 de diciembre de 1998, p. 17.

${ }^{29}$ Ibídem.

${ }^{30}$ HOGAN, Bernardo: "Sin torno", en Hogan: Sin torno. San Juan, P.R., 2001, s.f.

31 GARCÍA GUTIÉRREZ, Enrique: "Tres exhibiciones de cerámica”, El Nuevo Día, 11 de marzo de 2001, p. 9. 
prueba su capacidad de reinvención. El conjunto expuesto en Couturier Gallery debió componer, de hecho, no sólo un ansiado retorno a la rotación mecánica sino la oportunidad perfecta de continuar desarrollando más variaciones a partir de su giro. El propio Hogan diría: "Volví otra vez al torno y sigo en él porque pienso que en la vasija, si sobra, sobran formas. Siempre hay algo diferente en ella"32. No hay duda de que la esbeltez de estos trabajos resaltaba sobre la marcada planitud de sus precedentes. La serie Soft Vessel, por ejemplo, mostraba un ligero ensanchamiento en la mitad del cono, delimitada en su arranque y en su remate por distintos trazos de pigmento. Ese "healthy disrespect for the center axis" ${ }^{33}$ insistía, una vez más, en el recorrido circular de la obra, volviendo a enmarcarla en una visión panóptica que otorgaba igual importancia a cada uno de sus ángulos. Tuscany, por el contrario, repetiría modelos ya conocidos: a un menor espesor en sus frentes le añadiría una textura enriquecida con los tonos anaranjados presentes por su extensión. La muestra, clausurada en mayo de 2005, podía leerse como un capítulo más dentro de un complejo itinerario artístico, singularizado, por encima de todo, por su fidelidad y un firme compromiso hacia la vasija, considerada por Hogan, en definitiva, como "la base de la cerámica".

Fecha de recepción: 20 de mayo de 2015.

Fecha de aceptación: 20 de noviembre de 2015.

32 Véase la nota 4.

${ }^{33}$ GARCÍA GUTIÉRREZ, Enrique: "Bernardo Hogan: A Maker of Ceramic Vessels", en Bernardo Hogan: Recent Works. Los Angeles, California, 2005, s.f. 


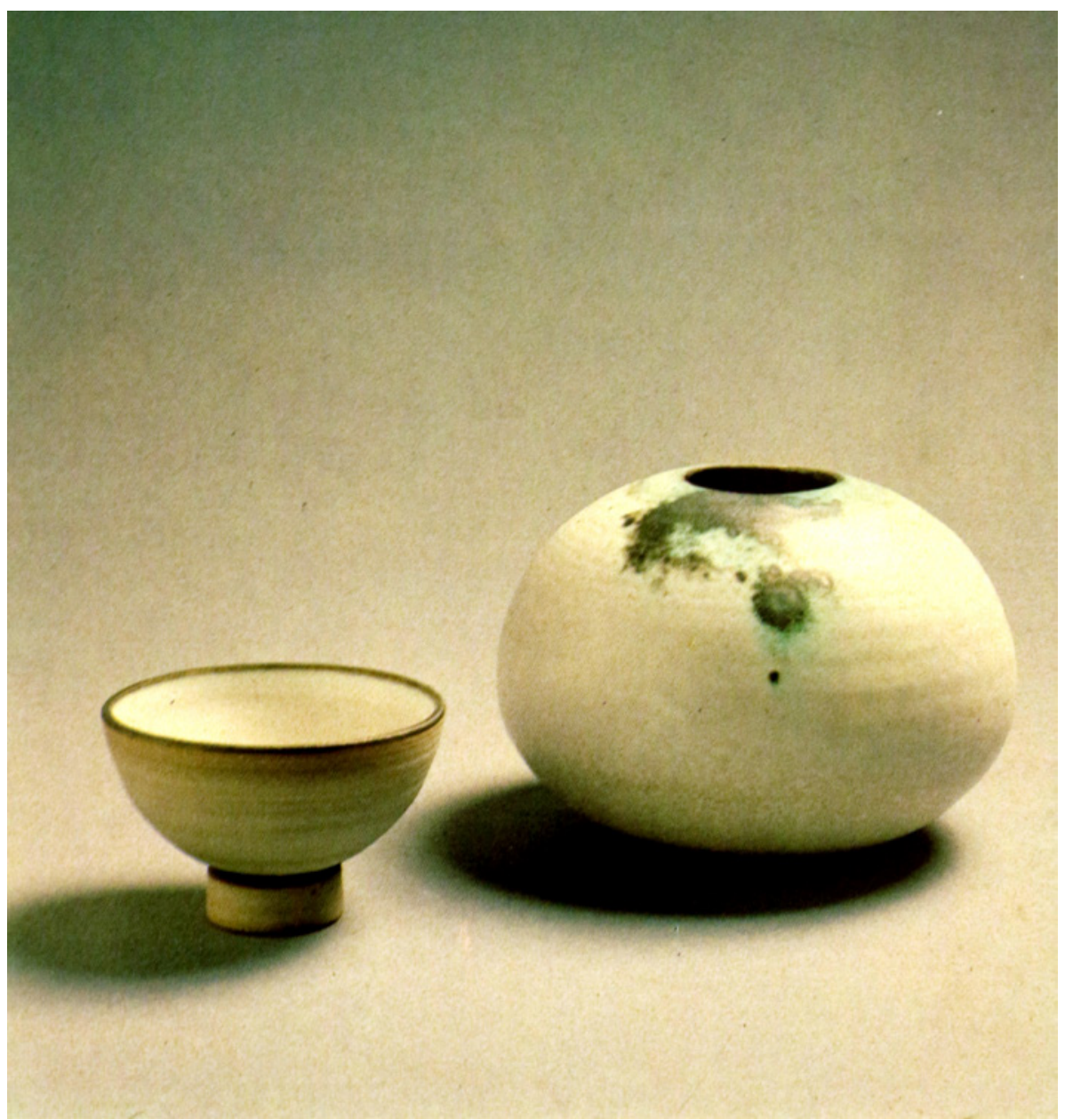

Figura 1. Dos de las piezas de Bernardo Hogan premiadas en el Concorso Internazionale della Ceramica d'Arte, celebrado en Faenza (1982). Fotografía: Cortesía Casa Candina. 


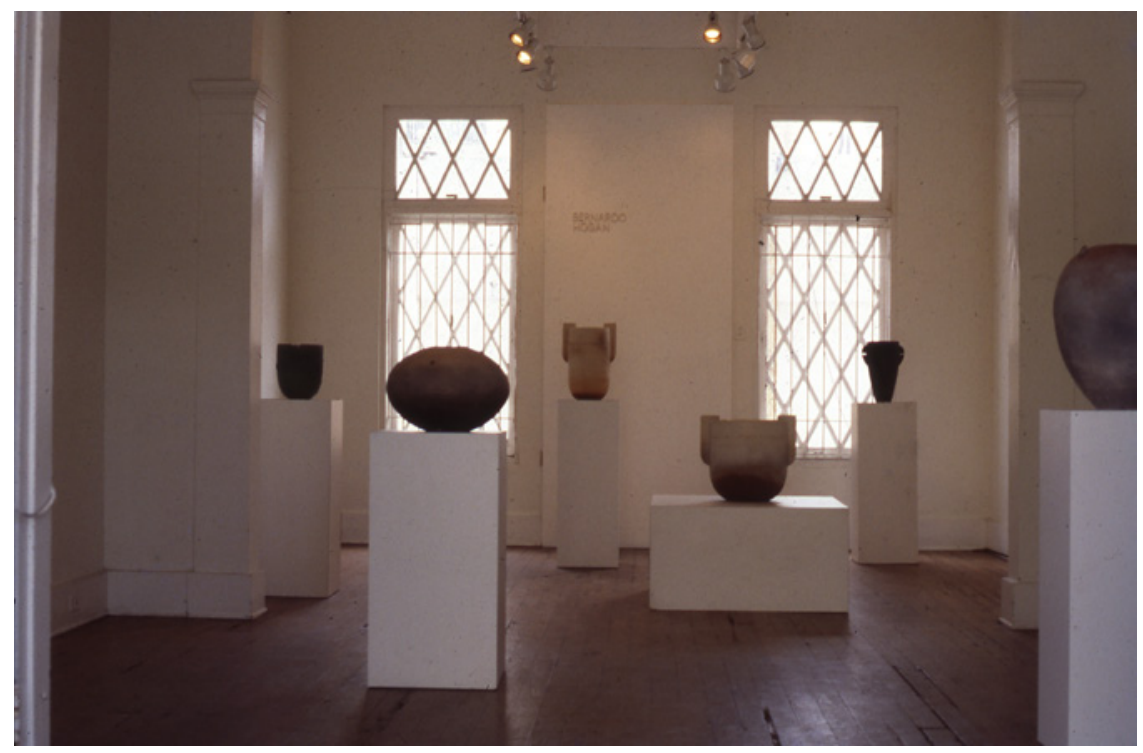

Figura 2. Montaje de la exposición Bernardo Hogan: Forma, textura y color, instalada en Casa Candina (1990). Fotografía: Cortesía Casa Candina.

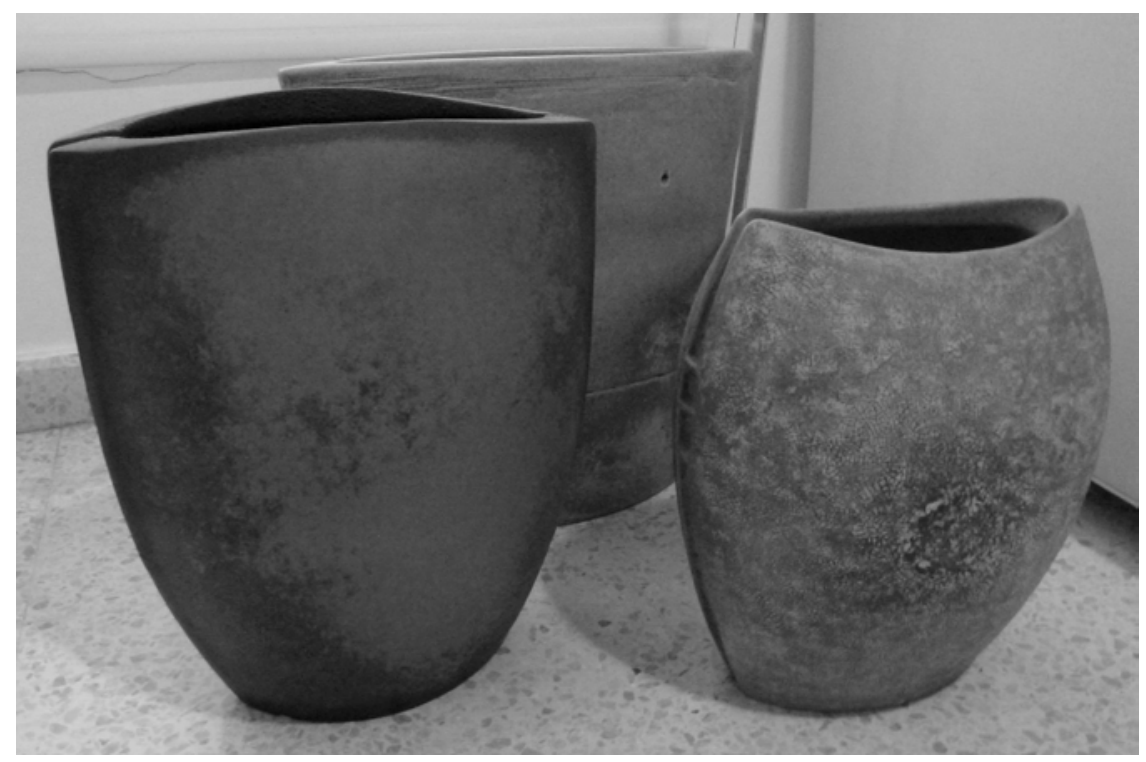

Figura 3. Algunas de las obras expuestas en El óvalo en la vasija, organizada en la Galería Botello (1998), y hoy en una colección particular de San Juan. Fotografía: Daniel Expósito Sánchez. 


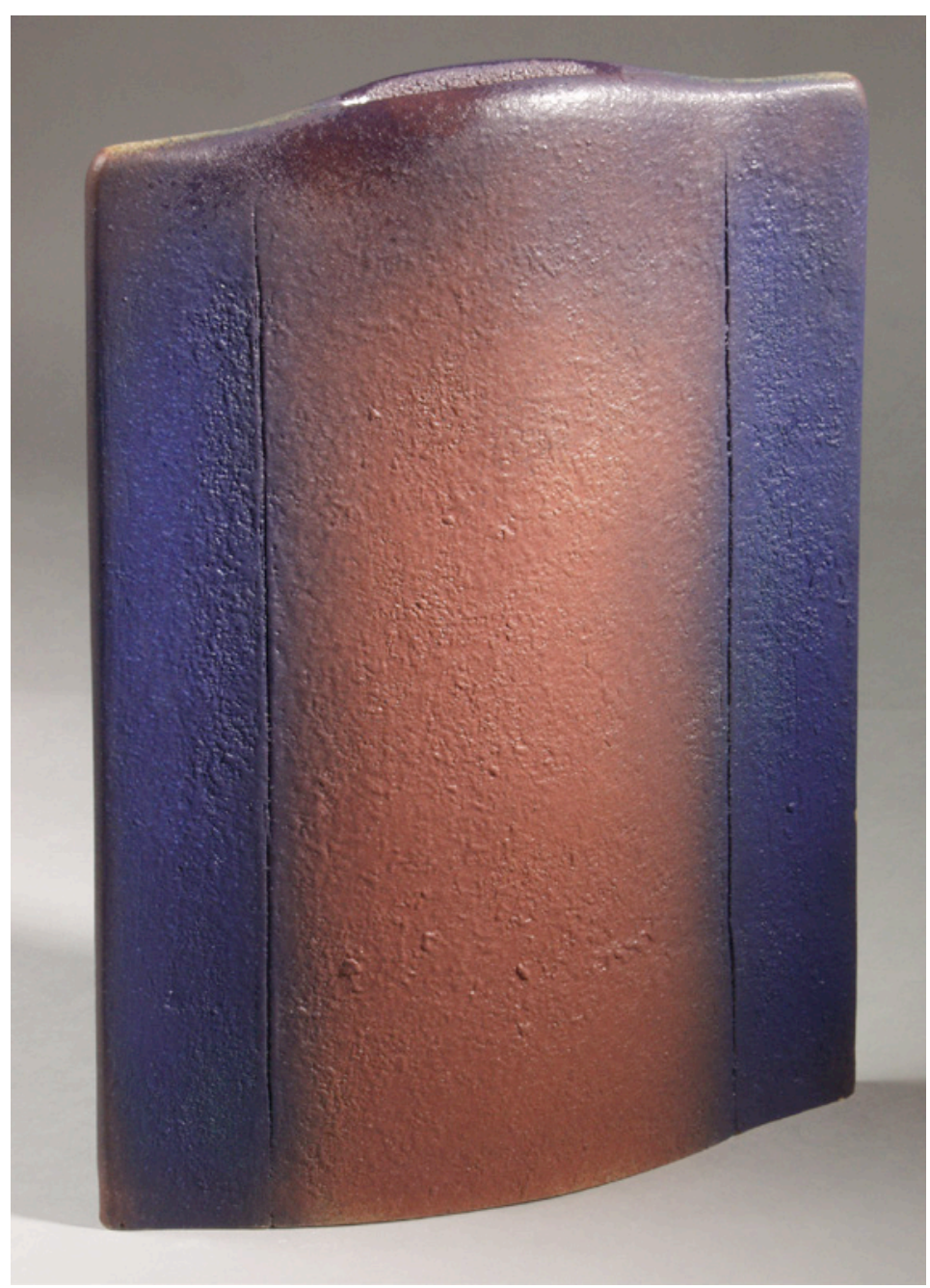

Figura 4. Una de las obras presentadas por el ceramista en la exposición Sin Torno, celebrada en la Galería Botello (2001). Fotografía: Cortesía Casa Candina. 


\section{BERNARDO HOGAN}

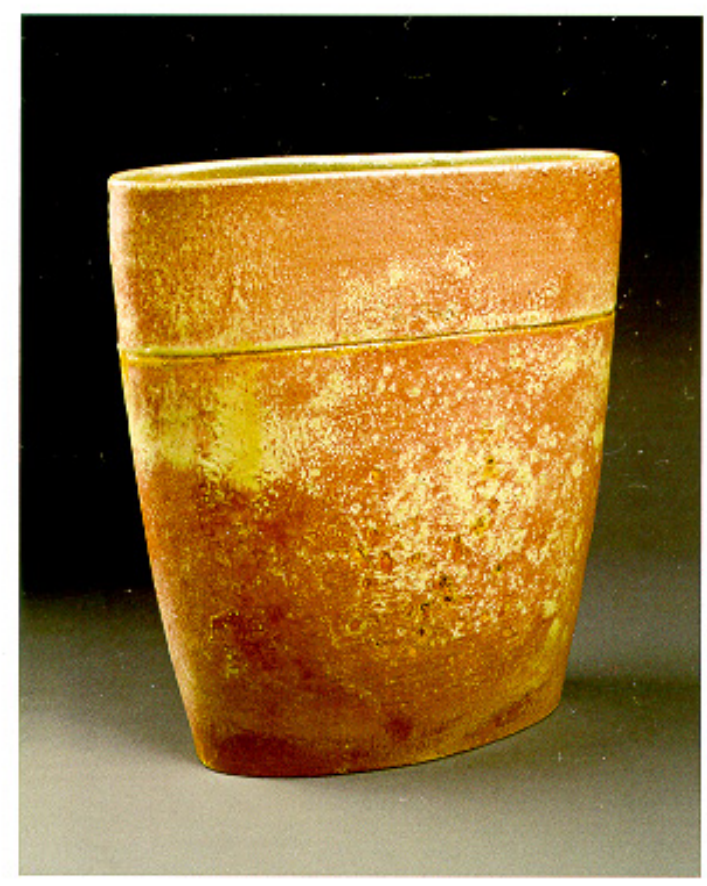

\section{Recent Works}

April 8 - May 21, 2005

Couturier Gallery, Los Angeles, California

Figura 5. Portada del folleto-catálogo publicado con ocasión de la última exposición individual de Bernardo Hogan, Recent Works, en Couturier Gallery (2005). Fotografía: Cortesía Casa Candina. 